\title{
Chapter 44 \\ Social Network Analysis and the Study of University Industry Relations
}

\author{
Fernando Cabrita Romero \\ University of Minho, Portugal
}

\begin{abstract}
The aim of this chapter is to give an overview of the use of social network analysis in the study of university industry relations. The structure of networks can be analyzed through the lens of social network analysis. This methodological approach is briefly described, and its fundamental concepts are presented. The chapter reviews the applications of this approach on the study of university industry relations. Different structures in the relations may result in different innovation outcomes, and the use of SNA may be particularly useful to understand differential outcomes. This chapter is based on a review of available literature on the topics. The chapter aims at systematizing the information and knowledge related to the application of SNA on university industry networks, highlighting the main research pathways, the main conclusions, and pointing to possible future research questions.
\end{abstract}

\section{INTRODUCTION}

The methodological approach of Social Network Analysis (from now on, abbreviated SNA) can bring many benefits for the study of university and industry relations (from now on, abbreviated UIR). Relations between university and industry are important in innovation studies because they can be considered as an innovation network, in the sense that the interactions established by their participants have more or less defined innovation goals (Mansfield \& Lee, 1996). SNA is the study of social structure (Wellman \& Berkowitz, 1988). It describes a group of quantitative methods for analysing the ties among social entities and their implications (Wasserman \& Faust, 2007). With the use of SNA it is possible to explore and to better understand different innovation outcomes involving UIR, by analysing the different measures and the structure of the social network. In this work the SNA methodological approach is described and its fundamental concepts are presented. The paper then reviews the applications of this approach on the

DOI: $10.4018 / 978-1-5225-7601-3 . c h 044$ 
study of the relationships between university and industry. The paper aims at systematizing the available information and knowledge, highlighting the main research pathways, the main conclusions and pointing possible future research questions.

\section{BACKGROUND}

UIR is an increasingly important and researched phenomena. Theoretically and structurally, the theme is linked to the study of the innovation process and to the need of understanding it and influencing it. Linear perspectives of the innovation process placed the university at the beginning of a linear sequence of innovation and the firm at the end of it, largely ignoring the interaction between the two types of institutions. New, interactive, dynamic, complex perspectives see the innovation process as a system involving many institutional actors, as a network of relations and as a complicated web of knowledge exchange and utilization. Science and technology are increasingly complex and costly and no single actor commands the necessary resources, relying on multiple sources of information and knowledge exchanges that are crucial for a successful innovation process. In this context, and considering the many types of relations and actors that may be possible in the innovation process, the relationships between academia and industry stand out as particularly relevant, because of the type of institutions that participate and the nature of the information and knowledge that is exchanged. The literature on UIR has raised many issues on the theme, and debates are ongoing, which can be found in some review articles (Baldwin \& Green, 1984; D’Este \& Patel, 2007; Perkmann et al., 2013). Only some of the issues and debates will be explored here, namely those researched by SNA concepts. They will be referred in more detail in the following section, along with the presentation of the results of the literature review, which is the main focus of this work.

SNA is the study of social structure using a group of quantitative methods. It analyses ties among social entities and looks for key players and group patterns. SNA uses concepts that are related to the structural properties of the network and indicators that are related to relational properties of the network. The most used concepts related to structural properties of the network in UIR studies are the concepts of density, component, and subgroups. The most used social network analysis concepts related to relational properties of the network are the concepts of degree centrality, betweenness centrality and geodesic distance.

The concepts related to structural properties of the network are basic and important concepts that characterize the overall structure of the network. Through the concept of density (which indicates the level of connection between all the nodes of the network) it characterizes its global cohesion. Through the concept of component (which indicates the existence of large groups inside the network) and through the concepts of subgroups or cliques (which indicates the existence of smaller, cohesive, specifically defined groups) it characterizes its internal structure. The combination of these indicators and an adequate interpretation of their meaning provides useful descriptions and characterizations of the network, in terms of the position of their nodes and constituents. The characterization is frequently complemented with visual aids, namely through sociograms. Sociograms are diagrams composed of nodes and lines. The nodes are the actors of the network and the lines are the connections between the actors. The concepts related to relational properties of the network are often at the centre of the analytic procedure, and are used in several ways according to specific research objectives. The concept of degree centrality (which 
indicates the extent of a node connection) identifies the most connected actors. The concept of betweenness centrality (which captures the intermediary nature of a particular node's connection) is used to identify and characterize the intermediary positions of actors in the network. Besides the main concepts referred above, other concepts related to these ones are also used, but less often. All these concepts are mathematically defined, but it is beyond the scope of this paper to provide detailed algebraic specifications, which are available in several books (Scott, 2000; Wasserman \& Faust, 2007).

\section{THE LITERATURE REVIEW}

\section{General Aspects and a Synthesis of the Main Results}

There is not a great number of articles that addresses specifically the problem of UIR using SNA techniques. There is a variety of perspectives that reflect specific and idiosyncratic concerns of the authors. Few papers follow the same guidelines or share identical perspectives. However, there are small groups of authors that build on past works or use identical databases, such as patent databases.

In terms of the main study object or main research preoccupation the studies can be classified in the following categories: 1) the study of the characteristics of personnel/institutional networks that are prominent in university-industry relations; these studies generally rely on the use of patents that are coproduced jointly by university and non-university members, and the patterns of collaboration are analysed; 2) the study of university-industry relations in the context of specific industrial settings or in the context of specific institutional conditions; these studies may rely also on patent databases but other types of data may be used, either primary data, obtained through questionnaires, or secondary data, obtained through diverse documental sources; 3 ) the contribution of the study of university-industry relations to the validation of theories; these studies also rely on a mix of patent, primary and secondary data.

In addition to these themes there are other themes that are addressed in these studies, either in a parallel way or as themes that frame the former or the research approach. The themes that could be common to the papers are, in broad terms, the three main themes above indicated but, within each one, the approach and main research concerns and targets are quite different. The literature will be analysed not through the lens of the broad themes, but through the details of the specific papers. This methodology will permit to extract from the papers the main academic debates and to highlight the respective contributions to knowledge. The next sections will perform that task. Table 1 synthesises the results.

The table indicates the main identified concepts on UIR that have been researched using SNA. It is possible to divide those concepts in four groups. The first one includes the two first concepts, which are related to intrinsic structural properties of the network. The second group includes the two following concepts, which are related to institutional and knowledge characteristics of the network. The third group includes the next three concepts, which are related to specific patterns found in networks. The fourth group includes the last two concepts of the table, which are related to the validation of existing theories. The last concept is related to the search for new methodological approaches, mainly related to the use of new data sets. The main results and the literature for each concept will be described and explored in the following sections. 
Table 1. University-industry relations and social network analysis: main debates and conceptual propositions arising from the literature review

\begin{tabular}{|c|c|c|}
\hline Main Concepts & References (Authors, Year) & Conceptual Propositions Proposed by the Literature \\
\hline $\begin{array}{l}\text { Strong and weak ties, } \\
\text { structural holes }\end{array}$ & $\begin{array}{l}\text { (Gilsing \& Duysters, 2008; Rost, } \\
\text { 2011; van der Valk, Chappin, \& } \\
\text { Gijsbers, 2011; Villanueva-Felez, } \\
\text { Molas-Gallart, \& Escriba-Esteve, } \\
\text { 2013) }\end{array}$ & $\begin{array}{l}\text { - Balanced social structures (strong ties with some weak ties) seem to } \\
\text { be more innovative. } \\
\text { - Differential outcomes on the nature of knowledge contingent on the } \\
\text { specific balance of the structure of social capital. }\end{array}$ \\
\hline $\begin{array}{l}\text { "Small worlds" } \\
\text { networks }\end{array}$ & $\begin{array}{l}\text { (Balconi, Breschi, \& Lissoni, 2004; } \\
\text { Guan \& Zhao, 2013; Protogerou, } \\
\text { Caloghirou, \& Siokas, 2013; van der } \\
\text { Valk et al., 2011) }\end{array}$ & $\begin{array}{l}\text { Networks with high clustering and short average geodesic paths are } \\
\text { more conducive to inventive or innovative activity. }\end{array}$ \\
\hline $\begin{array}{l}\text { Open-science and } \\
\text { proprietary technology }\end{array}$ & $\begin{array}{l}\text { (Balconi et al., 2004; Jason Owen- } \\
\text { Smith \& Powell, 2004) }\end{array}$ & $\begin{array}{l}\text { - The institutional attributes of open science and proprietary } \\
\text { technology influences network structure. } \\
\text { - Open science networks are more connected and dense than } \\
\text { proprietary networks that are more fragmented and disperse. }\end{array}$ \\
\hline $\begin{array}{l}\text { Knowledge base } \\
\text { and environment as } \\
\text { relational factors }\end{array}$ & $\begin{array}{l}\text { (Gilsing \& Duysters, 2008; Krätke } \\
\text { \& Brandt, 2008; Leydesdorff, } \\
\text { 2004; J. Owen-Smith, Riccaboni, } \\
\text { Pammolli, \& Powell, 2002; Plum \& } \\
\text { Hassink, 2011) }\end{array}$ & $\begin{array}{l}\text { Different knowledge bases affect network structural properties, the } \\
\text { position of individual entities in the network and their capacity to } \\
\text { access knowledge }\end{array}$ \\
\hline $\begin{array}{l}\text { Patterns of university- } \\
\text { industry relations }\end{array}$ & $\begin{array}{l}\text { (Gilsing \& Duysters, 2008; Krätke } \\
\& \text { Brandt, 2008; Leydesdorff, 2004) }\end{array}$ & $\begin{array}{l}\text { - Patterns are influenced by regional industrial structures. } \\
\text { - Biotechnology has a specific pattern of university-industry } \\
\text { interaction. }\end{array}$ \\
\hline $\begin{array}{l}\text { Public research } \\
\text { organizations as central } \\
\text { actors in innovation } \\
\text { networks }\end{array}$ & $\begin{array}{l}\text { (Breschi \& Catalini, 2010; De } \\
\text { Stefano \& Zaccarin, 2013; Lissoni, } \\
\text { 2010; Minguillo \& Thelwall, 2012; } \\
\text { Protogerou et al., 2013) }\end{array}$ & $\begin{array}{l}\text { - Academic authors-inventors assume more brokerage positions. } \\
\text { - Public research organization are at the centre of innovation } \\
\text { programmes. }\end{array}$ \\
\hline $\begin{array}{l}\text { Influence of } \\
\text { commercial orientation } \\
\text { on fundamental science } \\
\text { production }\end{array}$ & (Balconi \& Laboranti, 2006) & $\begin{array}{l}\text { Academics more connected to industry are more productive in } \\
\text { scientific terms. }\end{array}$ \\
\hline Industrial districts & $\begin{array}{l}\text { (Capo-Vicedo, Molina-Morales, \& } \\
\text { Capo, 2013; Morrison, 2008) }\end{array}$ & $\begin{array}{l}\text { - Public research organization as main intermediaries of knowledge } \\
\text { flows to the district. } \\
\text { - Weak knowledge exchanges but strong information exchanges inside } \\
\text { the district actors. }\end{array}$ \\
\hline Triple-helix theory & $\begin{array}{l}\text { (Heimeriks, Hörlesberger, \& Van } \\
\text { Den Besselaar, 2003; Khan \& Park, } \\
\text { 2013) }\end{array}$ & $\begin{array}{l}\text { - Triple helix assumptions on institutional role intersections are } \\
\text { supported. } \\
\text { - Multiple communication channels with differential roles in the Triple } \\
\text { Helix relation. }\end{array}$ \\
\hline $\begin{array}{l}\text { Methodological } \\
\text { contributions }\end{array}$ & $\begin{array}{l}\text { (Heimeriks et al., 2003; Kim, 2012; } \\
\text { Minguillo \& Thelwall, 2012) }\end{array}$ & $\begin{array}{l}\text { Asides from patents indicators, other indicators and data unmask } \\
\text { fundamental structural or relational properties. }\end{array}$ \\
\hline
\end{tabular}

\section{Strong and Weak Ties, and Structural Holes}

The influence of the nature of the relation on the performance of the network is a debated issue. The concepts of strong and weak ties were introduced by Granovetter (1973). Strong ties represents strong and regular interactions between the actors (nodes) of the network and weak ties represent sporadic and temporary interactions. 
Coleman (1988) claimed that cohesive groups and strong ties were effective ways to coordinate an exchange of knowledge flows, while Burt (1992) argued that strong ties resulted in redundant information and that innovation required new knowledge inflows and perspectives coming from weak ties. Unfulfilled connections between groups with internal strong ties are said to be structural holes, which can be filled by specific actors, with strong intermediary positions. Villanueva-Felez et al. (2013) apply these concepts to assess in which way the structure of researchers' social capital affects academic performance. The authors distinguish between academics that are completely embedded in a network that has no weak ties (establishing links with members of his or her own department, without ties with government, industrial, or other societal actors), academics which are in a network that is formed predominantly by weak ties, and academics that are in an integrated network that contains both strong and weak ties. The results show that the academics in the network with no weak ties are the less productive. On a study of a network of inventors and on the assessment of the impact of patents (based on forward citations) and integration of knowledge (based on backward citations), Rost (2011) concludes that inventors with balanced social capital (strong ties but also some weak ties) come up with the most innovative solutions, or integrate the most knowledge or have the highest impact on future knowledge. He concludes that Coleman's and Burt's perspectives are complementary and that in the presence of strong ties, weak network structures (structural holes or peripheral position) leverage the strength of strong ties in the creation of innovation. Similar arguments are advanced in a visual network analysis of two government sponsored programmes that aimed to foster innovation through public-private partnerships (van der Valk et al., 2011) and also by other studies of university-industry relations or industry networks (Ahuja, 2000; Gilsing \& Duysters, 2008).

\section{"Small Worlds" Networks}

The open science characteristics of scientific communities translate, in social network terms, into the so-called networks with "small worlds" characteristics (Albert \& Barabási, 2002). The small world properties, in the context of scientific networks in a specific discipline, are defined by the existence of a large component connecting almost all nodes and within the large component, all nodes (scientists) are close to each other (Albert \& Barabási, 2002; Newman, 2001). These characteristics of academic networks are not found in networks of non-academic inventors, except in since-based fields. The influence of small world properties on innovativeness is addressed in studies of industry networks (Verspagen \& Duysters, 2004) and in university-industry networks (Guan \& Zhao, 2013), and generally considered to be positive, although there are disagreements concerning this positive influence (Fleming, King Iii, \& Juda, 2007).

\section{Open Science and Proprietary Technology}

The analyses of patent databases provides the basis for the exploration of another important concept, which is debated in multiple forms and in its multiple consequences in studies of university-industry relations, which is the distinction between the characteristics of open science and proprietary technology (Cowan \& Jonard, 2003; Merton, 1957). The debate can be inserted in a larger debate concerning the influence of diverse institutional conditions on processes of relations between organizational entities. Balconi et al. (2004) conduct a study of Italian academic and industrial inventors whereby, departing from assumptions on the behaviour or characteristics of "open science" networks and "proprietary networks", expect to find differences between the networks of academic and non-academic inventor. In 
fact, the study found that networks of industrial inventors are much more fragmented than networks of academic inventors, except in the chemistry field (defined in a broad sense, i.e. including biotechnology). The chemistry sector, science-based field, was different because it was influenced by the institutional weight of scientific inputs in commercial technology.

\section{Knowledge Based and Environmental Conditions as Relational Factors}

Other articles support the importance of environmental factors in shaping specific properties of networks. A study of the Boston biotechnology sector (Jason Owen-Smith \& Powell, 2004) found that the information flows between the actors of the network, which included firms and public research organizations, depended not only on network participation and geographic proximity, but also on the institutional characteristics of the network. In public-dominated networks firm performance depended only on net participation, unlike in networks dominated by private entities, where innovative performance depended on position factors, i.e., their closeness to central actors (although this characteristic was weak in terms of statistical significance).

An important determinant of cooperation between university and industry, and an important factor in terms of innovative performance, seems to be related to the position of the firm in the network. That position may be related to geography (Balconi \& Laboranti, 2006) or that position may be related to the knowledge base that the firm possesses and that may confer the firm the possibility to connect with more or less central actors of the network. A study of an industrial network in Germany (Cantner \& Graf, 2006) argues that a prerequisite for future cooperation is not based on past cooperation but rather on a shared knowledge base. It puts in question ideas that argue that persistent cooperation, based on trust, is necessarily the basis for collaboration. In a study of two industrial networks (biotechnology and multimedia) in a period that was characterised by the transition of an existing dominant design and a shift away from rules, norms, routines or activities, Gilsing and Duysters (2008) argue that environmental conditions related to different knowledge bases, and the validation and selection mechanisms inherent to each of the two fields, explain the relational and structural properties of the two networks. For instance, the connection of public research organizations is centrally present in the biotechnology field but absent in the multimedia field (Gilsing \& Duysters, 2008).

Differences in the knowledge base show up as an important factor in the determination of collaboration structures in another study involving biotechnology firms in a regional context (Plum \& Hassink, 2011). It points to differences related to internal competencies of the firms regarding differential capabilities in terms of the nature of the knowledge required to develop the differential products of each firm, in which the knowledge of the market also has a role.

Although in a quite different perspective, a study of the differences between the structures of two networks emphasises the importance of environment in shaping the properties of the network (Capellari $\&$ De Stefano, 2014). Patents that are owned by the university (which is the assignee) or invented by the university (the university is not the assignee but at least one of the inventors is a tenured academic), are analysed separately, showing differences in terms of size of components, number and size of subgroups and the brokerage position of inventors. The institutional factors are mediated by two universities that have different policies related to patenting ownership. 


\section{Patterns of University-Industry Relations}

Databases on scientific literature have been extensively used to analyse the patterns of collaboration between scientists. Patent databases are also being explored to analyse the patterns of collaboration between academia and industry.

An exploratory analysis of the simultaneous embeddedness of researchers in scientific and technological networks (Breschi \& Catalini, 2010), which compares networks of authors, inventors and authorsinventors, and the overlap between them, argues that author-inventors play a crucial role in connecting the two other networks (only authors and only inventors) and occupy important positions in each community. The role of academics as fundamental intermediaries between public and private research is explored in a study (Lissoni, 2010) that founds that academic inventors tend to be more central actors in broker and gatekeeping positions, although strong brokerage positions are very few and held by scientist with many patents and publications. De Stefano and Zaccarin (2013) reach similar conclusions regarding the larger relational activity of academic authors-inventors vis-a-vis industrial authors-inventors.

Two important differences were also apparent in Balconi et al. (2004): academic inventors were more connected than non-academic inventors, and had a more central position. The central position of academics, or of the university, is a characteristic that often shows up in analysis of networks where public research organisations are involved (Balconi \& Laboranti, 2006; Breschi \& Catalini, 2010; Jason Owen-Smith \& Powell, 2004; Protogerou et al., 2013).

The knowledge base of patents is researched to see how much innovation is really based on science (Leydesdorff, 2004). This question is important because theories about university-industry relations are historically influenced by the biotechnology sector. The biotechnology is a science-based sector whose inventive activities tend to be performed in close collaboration with public research organizations and whose output is patented through co-authorships or co-assignments between academic and industrial inventors. The access and the analysis of patents databases have become easier and many studies have thus relied on these data to infer general conclusions to other fields of science, that are not so formalized in terms of literature relations. The study analysis two sets of patents, extracted from the USPTO, one based on patents that have a university as a co-assignee, and another that has a Dutch address as an assignee. The structure of the co-words networks linking patents and their citations to other patents and scientific literature is analysed. The analysis is entirely based on the visualization of sociograms, while nodes are (co)words). The two networks are quite different. In the set of university patents (which represents university-industry relations) the fields of biotechnology and molecular biology dominate the set and the knowledge base of the patents, and the visualising shows a neat organization around the intellectual organization of the disciplines. In the set of Dutch patents (representing the knowledge base of the international economy) the visualization shows a recognizable representation of the Dutch industrial structure with a dominance of electro-technical and chemical applications and large multinational corporations. Although biomedical application integrates the patents they are not central to the whole set. These results strongly suggest that inferences of university-industry relations based on literature and patent analyses are heavily conditioned by the specificity of the biotechnology sector.

\section{Public Research Organizations as Central Actors in Innovation Networks}

The central position of public research organizations shows up in descriptive analyses of networks that involve heterogeneous actors. Both a study of the network structure of science parks (Minguillo \& 
Thelwall, 2012), using web links as indicators of connections, and a study of the collaborative networks established during the seven Framework Programme on Research and Technological Development of European Commission, show the central position of public research organizations. In the study of science parks, governmental agencies also play an important role, and in the case of the Framework Programmes, although firms are present in larger numbers, they are not the central actors.

\section{Influence of Commercial Orientation on Fundamental Science}

The impact on fundamental research of an orientation to patenting and commercialization has been researched trough the relationship between patenting activity and publication record of university researchers, and in general the results point to a positive correlation between patenting and publication activity (Czarnitzki, Glänzel, \& Hussinger, 2009). This theme is revived with a social network approach (Balconi \& Laboranti, 2006) and the results support the positive relationship between publication record and patenting activity. The author argues, in line with other similar arguments (Rosenberg \& Nelson, 1994), that industry feeds on academic research but that academic research also needs inputs from high technology industries in order to find direction to its research. So, academics that are close and collaborate with industry producing patents are also the ones that are more productive in purely scientific terms.

\section{Industrial Districts}

There is a strand of research of university-industry relations using social network analysis methods that adopt a deductive approach and try to validate some relatively entrenched conceptual implications of some theories.

One of the researched theories looks at the implications of the industrial district approach. Morrison (2008), in her study of the furniture sector in Italy, argues that the community of informal ties appears to be rather small and that 'know how' sharing is also rather limited, contrary to assumptions from industrial district theorists that based their ideas on the development of these concentrated regions on intense knowledge exchange between the actors. It, however, supports the argument that public research organizations, more than large firms, play a central role and as intermediaries in the knowledge flows for innovation that occur in the industrial district, and that knowledge for innovation does not arise only from the close interactions of the firms of the district, an idea that is also supported by a study of a Spanish textile industrial district (Capo-Vicedo et al., 2013).

\section{Triple-Helix Theory}

The implications of the triple-helix approach are also examined. Using webometric indicators and semantic analysis of the contents of the webpages Kim (2012) found that university and industry websites were similar, thus suggesting there is an intersection or interchangeability of the roles and function of the two types of organizations, as suggested by the triple-helix theory (Etzkowitz \& Leydesdorff, 1998). Diverse channels of communication and relations between the diverse institutional actors (co-authorship, participation in projects, information diffusion) is also explored in Heimeriks et al. (2003) which argues that each communication channel or media has different functional purposes in maintaining in the maintenance of the links of the triple-helix relation. 


\section{Methodological Contributions}

Finally, there is a search for alternative methodological approaches and indicators in the studies of networks of university-industry relations. Some authors propose the use of webometric approaches (Kim, 2012; Minguillo \& Thelwall, 2012) and other authors propose the use of simultaneous indicators of relational characteristics, such as citations, project participation, questionnaires or other data (Almodovar \& Teixeira, 2014; Furukawa, Shirakawa, \& Okuwada, 2011; Heimeriks et al., 2003), arguing that analysis based on a single indicator underestimate the level and may not capture all of the complexities of the collaboration patterns.

\section{FUTURE RESEARCH DIRECTIONS}

Some possible research paths are open. Eventually, the use of more complex and elaborated concepts of network analysis could improve the analysis of data, it may have the potential to reach different or stronger evidence and conclusions, and it may be an aspect that must be improved. The diversity and plurality of university-industry relations has not been properly addressed in the literature, which tends to use patents as indicators of collaboration. New sources of data must be explored. Environmental and institutional influences of diverse sorts are clearly very important factors that condition and determine university-industry relations, and research is open to greater exploratory efforts. There is a considerable potential to test theoretical and conceptual propositions which are assumed but have scarce empirical support.

\section{CONCLUSION}

The use of social network analysis in the study of university-industry relations was reviewed in this study. There are not many studies that combine the two perspectives and the ones that exist follow different research objectives and concerns and different methodological proposals. It seems evident that this particular knowledge quest is in a highly exploratory phase. Nevertheless, the contributions to knowledge have been varied and important, ranging from purely descriptive studies and methodological explorations to deductive testing of established theories.

\section{REFERENCES}

Ahuja, G. (2000). Collaboration networks, structural holes, and innovation: A longitudinal study. Administrative Science Quarterly, 45(3), 425-455. doi:10.2307/2667105

Albert, R., \& Barabási, A.-L. (2002). Statistical mechanics of complex networks. Reviews of Modern Physics, 74(1), 47-97. doi:10.1103/RevModPhys.74.47

Almodovar, J., \& Teixeira, A. A. C. (2014). Assessing the Importance of Local Supporting Organizations in the Automotive Industry: A Hybrid Dynamic Framework of Innovation Networks. European Planning Studies, 22(4), 841-865. doi:10.1080/09654313.2013.771621 
Balconi, M., Breschi, S., \& Lissoni, F. (2004). Networks of inventors and the role of academia: an exploration of Italian patent data. Research Policy, 33(1), 127-145.

Balconi, M., \& Laboranti, A. (2006). University-industry interactions in applied research: The case of microelectronics. Research Policy, 35(10), 1616-1630. doi:10.1016/j.respol.2006.09.018

Baldwin, D. R., \& Green, J. W. (1984). University-Industry Relations - a Review of the Literature. SraJournal of the Society of Research Administrators, 15(4), 5-17.

Breschi, S., \& Catalini, C. (2010). Tracing the links between science and technology: An exploratory analysis of scientists and inventors networks. Research Policy, 39(1), 14-26. doi:10.1016/j.respol.2009.11.004

Burt, R. S. (1992). Structural Holes. Cambridge, MA: Harvard University Press.

Cantner, U., \& Graf, H. (2006). The network of innovators in Jena: An application of social network analysis. Research Policy, 35(4), 463-480. doi:10.1016/j.respol.2006.01.002

Capellari, S., \& De Stefano, D. (2014). University-owned and university-invented patents: A network analysis on two Italian universities. Scientometrics, 99(2), 313-329. doi:10.100711192-013-1211-5

Capo-Vicedo, J., Molina-Morales, F. X., \& Capo, J. (2013). The role of universities in making industrial districts more dynamic. A case study in Spain. Higher Education, 65(4), 417-435. doi:10.100710734012-9553-0

Coleman, J. S. (1988). Social capital in the creation of human capital. American Journal of Sociology, 94(Supplement), S95-S120. doi:10.1086/228943

Cowan, R., \& Jonard, N. (2003). The dynamics of collective invention. Journal of Economic Behavior \& Organization, 52(4), 513-532. doi:10.1016/S0167-2681(03)00091-X

Czarnitzki, D., Glänzel, W., \& Hussinger, K. (2009). Heterogeneity of patenting activity and its implications for scientific research. Research Policy, 38(1), 26-34. doi:10.1016/j.respol.2008.10.001

De Stefano, D., \& Zaccarin, S. (2013). Modelling Multiple Interactions in Science and Technology Networks. Industry and Innovation, 20(3), 221-240. doi:10.1080/13662716.2013.791130

DEste, P., \& Patel, P. (2007). University-industry linkages in the UK: What are the factors underlying the variety of interactions with industry? Research Policy, 36(9), 1295-1313.doi:10.1016/j.respol.2007.05.002

Etzkowitz, H., \& Leydesdorff, L. (1998). The endless transition: A triple helix of university-industrygovernment relations. Minerva, 36(3), 203-208. doi:10.1023/A:1004348123030

Fleming, L., King Iii, C., \& Juda, A. I. (2007). Small Worlds and Regional Innovation (Vol. 18). Academic Press.

Furukawa, T., Shirakawa, N., \& Okuwada, K. (2011). Quantitative analysis of collaborative and mobility networks. Scientometrics, 87(3), 451-466. doi:10.100711192-011-0360-7

Gilsing, V. A., \& Duysters, G. M. (2008). Understanding novelty creation in exploration networksStructural and relational embeddedness jointly considered. Technovation, 28(10), 693-708. doi:10.1016/j. technovation.2008.03.004 
Granovetter, M. (1973). The Strenght of Weak Ties. American Journal of Sociology, 78(6), 1360-1380. doi:10.1086/225469

Guan, J. C., \& Zhao, Q. J. (2013). The impact of university-industry collaboration networks on innovation in nanobiopharmaceuticals. Technological Forecasting and Social Change, 80(7), 1271-1286. doi:10.1016/j.techfore.2012.11.013

Heimeriks, G., Hörlesberger, M., \& Van Den Besselaar, P. (2003). Mapping communication and collaboration in heterogeneous research networks. Scientometrics, 58(2), 391-413. doi:10.1023/A:1026296812830

Khan, G. F., \& Park, H. W. (2013). The e-government research domain: A triple helix network analysis of collaboration at the regional, country, and institutional levels. Government Information Quarterly, 30(2), 182-193. doi:10.1016/j.giq.2012.09.003

Kim, J. H. (2012). A Hyperlink and Semantic Network Analysis of the Triple Helix (University-Government-Industry): The Interorganizational Communication Structure of Nanotechnology. Journal of Computer-Mediated Communication, 17(2), 152-170. doi:10.1111/j.1083-6101.2011.01564.x

Krätke, S., \& Brandt, A. (2008). Knowledge Networks as a Regional Development Resource: A Network Analysis of the Interlinks between Scientific Institutions and Regional Firms in the Metropolitan region of Hanover, Germany. European Planning Studies, 17(1), 43-63. doi:10.1080/09654310802513930

Leydesdorff, L. (2004). The University-Industry Knowledge Relationship: Analyzing Patents and the Science Base of Technologies. Journal of the American Society for Information Science and Technology, 55(11), 991-1001. doi:10.1002/asi.20045

Lissoni, F. (2010). Academic inventors as brokers. Research Policy, 39(7), 843-857. doi:10.1016/j. respol.2010.04.005

Mansfield, E., \& Lee, J. (1996). The modern university: Contributor to industrial innovation and recipient of industrial R\&D support. Research Policy, 25(7), 1057-1058. doi:10.1016/S0048-7333(96)00893-1

Merton, R. K. (1957). Priorities in Scientific Discovery: A Chapter in the Sociology of Science. American Sociological Review, 22(6), 635-659. doi:10.2307/2089193

Minguillo, D., \& Thelwall, M. (2012). Mapping the network structure of science parks An exploratory study of cross-sectoral interactions reflected on the web. Aslib Proceedings, 64(4), 332-357. doi:10.1108/00012531211244716

Morrison, A. (2008). Gatekeepers of Knowledge within Industrial Districts: Who They Are, How They Interact. Regional Studies, 42(6), 817-835. doi:10.1080/00343400701654178

Newman, M. E. J. (2001). The structure of scientific collaboration networks. Proceedings of the National Academy of Sciences of the United States of America, 98(2), 404-409. doi:10.1073/pnas.98.2.404 PMID:11149952

Owen-Smith, J., \& Powell, W. W. (2004). Knowledge Networks as Channels and Conduits: The Effects of Spillovers in the Boston Biotechnology Community. Organization Science, 15(1), 5-21. doi:10.1287/ orsc. 1030.0054 
Owen-Smith, J., Riccaboni, M., Pammolli, F., \& Powell, W. W. (2002). A comparison of US and European university-industry relations in the life sciences. Management Science, 48(1), 24-43. doi:10.1287/ mnsc.48.1.24.14275

Perkmann, M., Tartari, V., McKelvey, M., Autio, E., Broström, A., DEste, P., ... Sobrero, M. (2013). Academic engagement and commercialisation: A review of the literature on university-industry relations. Research Policy, 42(2), 423-442. doi:10.1016/j.respol.2012.09.007

Plum, O., \& Hassink, R. (2011). On the Nature and Geography of Innovation and Interactive Learning: A Case Study of the Biotechnology Industry in the Aachen Technology Region, Germany. European Planning Studies, 19(7), 1141-1163. doi:10.1080/09654313.2011.573128

Protogerou, A., Caloghirou, Y., \& Siokas, E. (2013). Twenty-five years of science-industry collaboration: The emergence and evolution of policy-driven research networks across Europe. The Journal of Technology Transfer, 38(6), 873-895. doi:10.100710961-012-9278-3

Rosenberg, N., \& Nelson, R. R. (1994). American universities and technical advance in industry. Research Policy, 23(3), 323-348. doi:10.1016/0048-7333(94)90042-6

Rost, K. (2011). The strength of strong ties in the creation of innovation. Research Policy, 40(4), 588-604. doi:10.1016/j.respol.2010.12.001

Scott, J. (2000). Social network analysis: a handbook. London: Sage Publications.

van der Valk, T., Chappin, M. M. H., \& Gijsbers, G. W. (2011). Evaluating innovation networks in emerging technologies. Technological Forecasting and Social Change, 78(1), 25-39. doi:10.1016/j. techfore.2010.07.001

Verspagen, B., \& Duysters, G. (2004). The small worlds of strategic technology alliances. Technovation, 24(7), 563-571. doi:10.1016/S0166-4972(02)00123-2

Villanueva-Felez, A., Molas-Gallart, J., \& Escriba-Esteve, A. (2013). Measuring Personal Networks and Their Relationship with Scientific Production. Minerva, 51(4), 465-483. doi:10.100711024-013-9239-5

Wasserman, S., \& Faust, K. (2007). Social network analysis: Methods and applications. Cambridge, UK: Cambridge University Press.

Wellman, B., \& Berkowitz, S. (1988). Social structures: A network approach. Cambridge, UK: Cambridge University Press.

\section{KEY TERMS AND DEFINITIONS}

Betweenness Centrality: A social network analysis measure that indicates how much a node is in the middle of the connections between other nodes.

Degree Centrality: A social network analysis measure that indicates the number of other nodes to which the node is connected. 
Density: A social network analysis measure that describes the level of linkages between nodes in a network. The more nodes are connected to each other, the denser the network is.

Innovation Process: Is a complex social and technical process that transforms ideas and technologies into new or improved products or services.

Open Science: Open science is generally, but not exclusively, performed in university settings and is characterized by the wide non-commercial dissemination of research results and scientific knowledge.

Proprietary Technology: Is characterized by the appropriation by private entities of specific claims on technology, generally, but not exclusively, through the legal mechanism of patenting.

Social Network Analysis: A methodological approach that employs quantitative techniques to analyse social structures.

Strong and Weak Ties: A strong tie represents a person with whom there is a regular interaction, and a weak tie represents a person with whom there are sporadic or punctual contacts.

Structural Holes: The connection potential between elements or groups of elements that are not connected.

University-Industry Relations: A set of connections between people in university and people in industry. There are many forms of relations, including informal ones (the flow of graduates to industry, mobility of researchers, public meetings, professional networks) and formal ones (research contracts, licensing, joint labs).

This research was previously published in the Encyclopedia of Information Science and Technology, Fourth Edition edited by Mehdi Khosrow-Pour, pages 7150-7160, copyright year 2018 by Information Science Reference (an imprint of IGI Global). 